\title{
STRATEGY OF GREEN DESIGN IMPLEMENTATION FOR OPTIMIZINg Of The NATURAL Ventilation at High-RISE BUILDing
}

\author{
STRATEGI IMPLEMENTASI DESAIN HIJAU \\ untuk Optimalisasi PenghawaAn Alami Pada Bangunan Tinggi
}

\author{
Juliana Bekti Susilaning Budi ${ }^{1 *}$, Khairunnisa Fifthariski ${ }^{2}$, Sri Yuliani ${ }^{3}$, Wiwik Setyaningsih ${ }^{4}$ \\ Department of Architecture, Engineering Faculty, Universitas Sebelas Maret ${ }^{1}$ \\ julianabekti@ student.uns.ac.id** \\ Department of Architecture, Engineering Faculty, Universitas Sebelas Maret $^{2}$ \\ Department of Architecture, Engineering Faculty, Universitas Sebelas Maret ${ }^{3}$ \\ Department of Architecture, Engineering Faculty, Universitas Sebelas Maret ${ }^{4}$
}

\begin{abstract}
The natural air conditioning of high building contribute to save energy in building. Optimal of natural ventilation stabilities with the support of green design within a building can increase the level of thermal comfort and supports a spirit performance for user activity. The purpose of the research is to optimize the natural ventilation system applied in the building that is on the void located in the middle of the building by providing green space placed based on principles in green architecture. Research location is at building of Faculty of Medicine Universitas Sebelas Maret, focused at hall of The Medical Education Building. This research uses a description qualitative method based on literartur study, field observation and interview result with user. The final result from the provision of green design in the hall space of the building is the optimal natural air ventilation to achieve comfort zone, healthy and efficiency energy.
\end{abstract}

Keywords: natural ventilation, high building, green design

\section{PENDAHULUAN}

Kenyamanan termal merupakan suatu kondisi udara dalam ruang yang dirasakan oleh seseorang sehingga memperoleh tingkat kepuasan berada di dalam lingkungannya. (American Society of Heating Refrigating Air Conditioning Engineer, 1992). Kenyamanan termal menjadi salah satu faktor yang dibutuhkan dalam suatu ruang agar dapat memberikan rasa nyaman kepada pengguna dalam beraktifitas di dalam bangunan. Kenyamanan termal dalam suatu bangunan dipengaruhi oleh beberapa faktor diantaranya adalah pengkondisian udara meliputi penghawaan alami dan penghawaan buatan. Penghawaan alami merupakan proses pertukaran udara di dalam bangunan melalui bantuan elemen-elemen bangunan yang terbuka dan terjadi akibat adanya perbedaan tekanan udara atau perbedaan suhu udara pada bagian luar dan dalam bangunan. Penghawaan alami merupakan bagian dari strategi desain arsitektur hijau yang diterapkan melalui adaptasi dengan iklim setempat. Beberapa faktor yang dipertimbangkan pada desain penghawaan alami yakni arah sinar matahari ke bangunan, terang langit, kelembaban, dan sistem bukaan. Penghawaan alami dapat memberikan kenyamanan pada pengguna bangunan karena aliran udara mempercepat proses penguapan di permukaan kulit sehingga dapat memberikan kesejukan bagi penghuni bangunan. Selain itu, penghawaan alami juga sangat penting bagi kesehatan karena dalam bangunan terdapat banyak uap air dari berbagai macam aktivitas dan uap air ini cenderung mengendap di dalam 
ruangan. Jika bangunan tidak memiliki sirkulasi udara yang baik maka zat-zat kimia tersebut akan tertinggal di dalam ruangan dan dapat terhirup oleh pengguna bangunan. Oleh karena itu, peran penghawaan alami sangat dibutuhkan dalam suatu bangunan untuk mencapai sebuah kenyamanan termal bagi pengguna bangunan. Optimalisasi penghawaan alami dapat diimplementasikan dengan desain hijau pada bangunan.

Salah satu bangunan bertingkat di kompleks kampus UNS adalah Gedung Pendidikan Dokter Fakultas Kedokteran Universitas Sebelas Maret Surakarta. Gedung ini memiliki tujuh lantai dan satu basement yang dimanfaatkan untuk kegiatan belajar mengajar mahasiswa kedokteran. Penerapan sistem penghawaan alami berpusat pada bagian hall lantai satu gedung yang dilengkapi dengan void menerus dari lantai dasar hingga lantai teratas bangunan. Void juga dilengkapi dengan penerapan skylight sebagai pendukung pencahayaan alami dalam bangunan. Namun sayangnya, penghawaan alami yang diterapkan dalam bangunan dirasa belum optimal. Hal ini disebabkan karena udara panas yang masuk melalui hall pada lantai satu tidak dapat bersirkulasi secara maksimal dalam bangunan. Udara panas ini masuk melalui hall kemudian naik menuju selasar-selasar setiap lantai melalui void sehingga menyebabkan udara pada selasar menjadi panas. Selain itu panas pada selasar juga didukung oleh suhu tinggi pada bangunan yang disebabkan oleh paparan sinar matahari karena bangunan menghadap ke arah barat dan terganggunya sistem penghawaan alami pada bangunan karena arah aliran udara masuk yang berada di sebelah utara dan selatan bangunan terhalang oleh ketinggian bangunan yang berada pada kedua sisi tersebut. Oleh karena itu, penghawaan alami yang sudah diterapkan dalam bangunan, perlu ditinjau lebih lanjut agar bangunan dapat memberikan kenyamanan termal yang maksimal pada pengguna.

Penyediaan ruang hijau pada bangunan merupakan salah satu solusi yang dapat mengatasi kurang optimalnya penghawaan alami yang diterapkan dalam bangunan. Ruang hijau ini nantinya akan diletakkan pada bagian bawah void dan tepat berada di bawah skylight sehingga angin panas yang masuk melalui hall lantai satu bangunan dapat didinginkan oleh tanaman pada ruang hijau yang ada di tengah bangunan kemudian angin dengan suhu rendah dan tekanan yang tinggi ini akan naik melalui void bangunan menuju selasar-selasar setiap lantai. Udara dengan suhu rendah dan tekanan tinggi ini naik karena menggantikan udara dengan suhu tinggi dan tekanan rendah akibat panas yang ditimbulkan dari pemasangan skylight pada atap bangunan. Pergantian udara dengan kualitas yang lebih baik diharapkan dapat mendukung kenyamanan termal pada bangunan sehingga dapat memberikan kenyamanan bagi pengguna gedung.

Penelitian ini bertujuan untuk mengoptimalkan sistem pengahawaan alami yang diterapkan dalam bangunan gedung pendidikan dokter Fakultas Kedokteran Universitas Sebelas Maret melalui strategi desain hijau dengan penyediaan ruang hijau berupa taman yang diletakkan pada bagian bawah void bangunan yang terletak di hall lantai satu sehingga dapat mendukung kenyamanan termal bangunan dan dapat menciptakan rasa nyaman bagi pengguna gedung khususnya pada hall lantai satu dan selasar setiap lantai bangunan sesuai dengan prinsip-prinsip dalam desain arsitektur.

Manfaat dari penelitian ini untuk menemukan strategi implementasi green design dengan optimalisasi sistem penghawaan alami melalui penyediaan ruang hijau pada hall lantai satu Gedung Pendidikan Dokter Fakultas Kedokteran Universitas Sebelas Maret berdasarkan evaluasi yang telah dilakukan dan menciptakan rasa nyaman bagi pengguna gedung khususnya pada hall lantai satu dan selasar tiap lantai bangunan sesuai dengan prinsip-prinsip dalam desain arsitektur.

Teori pendukung yang digunakan pada penyelesaian masalah dalam penelitian ini yaitu teori mengenai penghawaan alami, teori kenyamanan termal dan teori arsitektur hijau. Penghawaan alami atau yang sering disebut dengan ventilasi alami merupakan proses pertukaran udara yang terjadi didalam bangunan dengan memanfaatkan sisi-sisi bangunan yang terbuka. Kenyamanan dan kesejukan akan tercipta dengan adanya sirkulasi udara yang baik dan aliran udara yang mempercepat proses penguapan pada permukaan kulit bangunan. Proses pertukaraan 
udara tersebut juga memiliki banyak manfaat bagi kesehatan manusia. Adanya pertukaran udara ini akan menghilangkan reaksi bahan kimia berbahaya antara endapan uap air hasil dari kegiatan manusia dengan zat-zat kimia yang terkandung dalam pelapis dinding dan benda-benda dalam ruang. Zat-zat berbahaya tersebut akan terhirup oleh manusia jika tidak ada sirkulasi udara yang baik dalam ruang dan dapat menimbulkan penyakit dalam tubuh.

Untuk memaksimalkan aliran angin sebagai penghawaan alami, dibutuhkan aliran udara yang masuk melalui bukaan yang berjumlah lebih dari satu dengan posisi yang berseberangan, untuk menciptakan adanya ventilasi silang atau cross ventilation. Sistem ventilasi silang atau cross ventilation ini merupakan sebuah sistem untuk menghadirkan penghawaan alami dalam bangunan dengan cara memposisikan bukaan yang ideal yaitu secara berhadapan. Udara masuk melalui bukaan penerima angin lalu dialirkan ke bukaan yang berada diseberangnya. Hal ini ditujukan agar kelangsungan pertukaran udara tetap terjaga dan membuat penghuni merasa nyaman dalam ruangan. Hasil aktivitas manusia berupa bernafas, merokok, memasak dan lain-lain mengandung $\mathrm{CO} 2$ (karbondiaoksida) sehingga udara dalam ruang harus selalu berganti agar udara yang banyak mengandung $\mathrm{CO} 2$ akan berganti dengan udara yang mengandung $\mathrm{O} 2$ (oksigen) dari luar.

Terdapat dua jenis bukaan dalam sistem cross ventilation ini, yaitu bukaan inlet dan bukaan outlet. Bukaan inlet adalah bukaan yang berperan sebagai penerima angin sehingga posisinya menghadap arah datang angin dan bukaan outlet adalah bukaan yang berperan sebagai tempat keluarnya angin dari ruangan. Bukaan inlet dan outlet dapat berupa lubang angin, jendela hidup, kisi-kisi, pintu dan atau pembatas ruang yang dapat mengalirkan udara seperti terbuat dari kasa atau memiliki jalusi.

Dalam sistem cross ventilation terdapat dua jenis peletakan bukaan inlet dan outlet agar terciptanya aliran udara yang optimal yaitu peletakan berdasarkan arah datang angin posisi diagonal dan posisi berhadapan langsung. Posisi diagonal digunakan ketika arah datang angin tegak lurus ke arah bukaan inlet (penggambaran posisi diagonal dapat di lihat pada Gambar 1) dan posisi berhadapan langsung digunakan ketika arah datang angin bersudut atau tidak tegak lurus ke arah bukaan inlet (penggambaran posisi berhadapan langsung dapat di lihat pada Gambar 1).

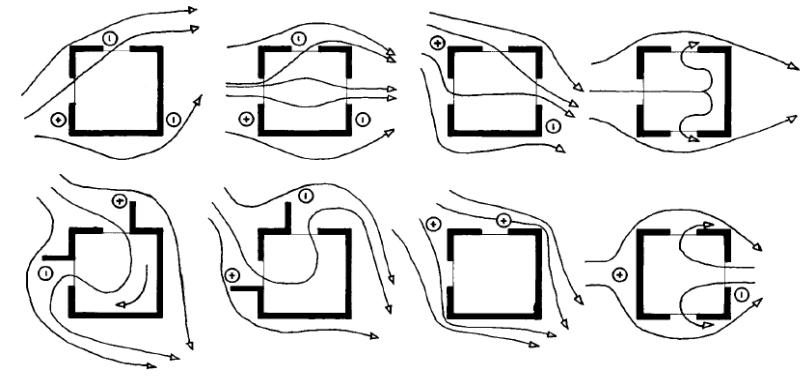

Gambar 1. Pergerakan udara dengan berbagai posisi bukaan.

Sumber: Stephen and Andrew, 2004.

Namun dalam pengaplikasiannya, terkadang perletakan bukaan tidak dapat disusun seperti teknik yang ideal. Hal tersebut disebabkan karena bidang yang mengarah keluar tidak saling berhadapan dan adanya faktor keterbatasan lahan sehingga terdapat ruang yang hanya memiliki satu bidang menghadap ke luar bangunan. Untuk mengatasi kondisikondisi tersebut, cross ventilation diterapkan dengan penambahan sirip-sirip vertikal pada tepian bukaan yang berperan sebagai pengarah udara masuk dan keluar bangunan. Sirip-sirip tersebut dapat berupa batu bata, kayu maupun beton. Adapun penggambaran posisi cross ventilation dengan berbagai posisi bukaan yang berbeda-beda memliki pola pergerakan udara yang bervariasi seperti pada Gambar 1 .

Bukaan inlet dan outlet juga dapat diletakkan atau disusun secara vertikal. Posisi inlet dan outlet yang ideal yaitu posisi inlet diletakkan lebih rendah dari outlet. Hal tersebut dikarenakan udara sejuk akan mengalir dari ketinggian yang sama dengan tubuh manusia menuju outlet yang berada diatas, sehingga tubuh manusia dapat merasakan kesejukan. Untuk memperoleh cross ventilation yang sempurna, posisi bukaan inlet diletakkan pada ketinggian aktivitas manusia yaitu sekitar 50 hingga $80 \mathrm{~cm}$ dan posisi outlet diletakkan lebih tinggi untuk mengeluarkan udara panas dari ruangan. Salah satu posisi peletakkan outlet yaitu diletakkan pada atap yang menggunakan jenis atap Jack Roof. Pada atap Jack Roof, kisikisi pada lubang antara atap induk dan atap topi 
berperan sebagai tempat keluarnya udara panas. Posisi ini sangat efektif karena udara panas yang terkumpul lebih banyak dibagian atas dapat keluar dari ruangan. Adapun penggambaran posisi inlet dan outlet pada atap Jack Roof dapat di lihat pada Gambar 2.

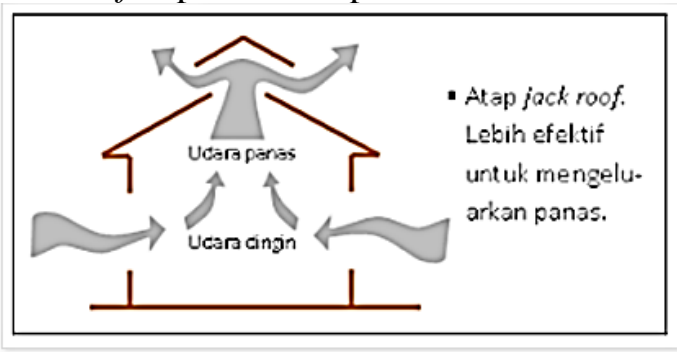

Gambar 2. Atap Jack Roof

Sumber: http://slendroo.blogspot.co.id/2011/10/ penghawaan-alami.html

Kenyamanan termal menurut Robert Mc Dowell adalah suatu kondisi dari pikiran yang mengungkapkan kepuasan terhadap lingkungan termal dimana hal tersebut dipengaruhi oleh subjektivitas setiap orang masing-masing.

Robert McDowell (Fundamental of HVAC System, 2008, p32-42) menyebutkan ada beberapa faktor yang mempengaruhi kenyamanan suhu yaitu :

a. Aktivitas pengguna. Metabolisme yang dilakukan oleh tubuh akan menghasilkan panas dimana energi panas minimum keluar pada saat tertidur dan akan meningkat ketika mulai beraktivitas seperti duduk, berjalan, dan berlari.

b. Jenis Pakaian. Penggunaan pakaian juga menentukan bagaimana melepaskan panas dari tubuh karena apabila kita menggunakan pakaian yang bersifat insulator tentunya akan merasa nyaman pada suhu yang lebih rendah.

c. Suhu Udara. Suhu udara mengalami perbedaan antara kepala dan kaki sehingga terkadang sulit menentukan suhu ideal bagi tubuh. Namun untuk daerah tropis suhu ideal tubuh berkisar $24-28^{\circ} \mathrm{C}$.

d. Radiasi Suhu. Ruang intervensi tidak mempengaruhi panas yang disalurkan dari benda yang lebih panas ke benda yang dingin karena setiap benda memiliki koefisien sendiri dalam memancarkan radiasi panas. Lantai, langit-lamgit, dan dinding pada bangunan memiliki panas yang sama namun akan berbeda ketika seseorang duduk di dekat jendela karena akan terasa bagaimana panas akan terkonveksi lewat kaca.

e. Kelembaban. Kelembaban dapat dikategorikan menjadi rendah dan tinggi. Kelembaban dapat dikatakan rendah apabila pada kulit dan mata seseorang terasa kering dan kelembaban dapat dikatakan tinggi apabila konsentrasi air dalam udara mencapai $100 \%$ pada $16^{\circ} \mathrm{C}$.

f. Kecepatan Udara. Kecepatan udara sangat mempengaruhi pendinginan pada tubuh manusia dimana semakin tinggi kecepatan udara di atas tubuh manusia maka akan semakin besar efek pendinginan dan kecepatan minimal yang dibutuhkan yaitu $0.2 \mathrm{~m} / \mathrm{s}$.

Selain aktivitas, jenis pakaian, suhu udara, radiasi suhu, kelembaban, kecepatan udara, kenyamanan termal suatu bangunan juga dipengaruhi oleh pemanfaatan tumbuhan pada lokasi bangunan itu berada. (Dea Sekar D.A., Gunawan, Sri Yuliani, 2018). Hal ini dikarenakan tumbuhan dapat menyebabkan adanya penurunan suhu sekitar lingkungan sehingga dapat memberikan efek sejuk pada bangunan dan dapat berperan sebagai penyuplai oksigen.

Adapun penggambaran skema faktor-faktor kenyamanan termal dapat di lihat pada Gambar 3.

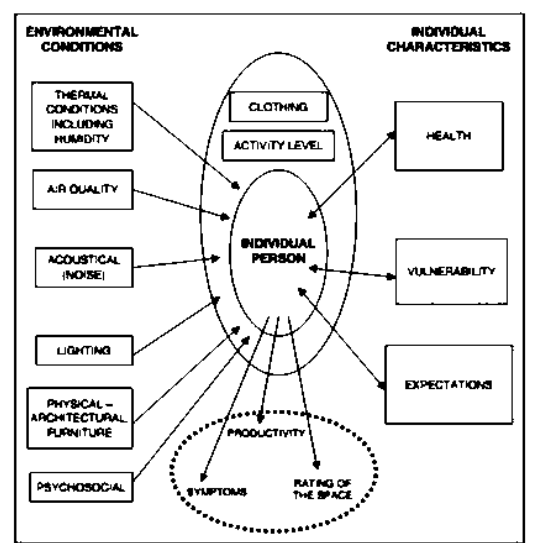

Gambar 3. Faktor-faktor kenyamanan termal Sumber: Robert McDowall (Fundamental of HVAC System, 2008, p32-42)

Ruang terbuka hijau adalah area memanjang atau jalur dan atau mengelompok yang penggunaanya bersifat terbuka dan merupakan tempat tumbuh tanaman baik secara alamiah 
maupun buatan (Undang-Undang No.26 tentang Penataan Ruang). Ruang terbuka hijau terabagi menjadi dua yaitu ruang terbuka hijau publik dan ruang terbuka hijau privat. Ruang terbuka hijau publik adalah ruang terbuka hijau yang dimiliki dan dikelola pemerintah daerah kota serta digunakan untuk kepentingan masyarakat. Ruang terbuka hijau publik misalnya taman kota, taman pemakaman umum, dan jalur hijau sepanjang jalan, sungai, dan pantai. Sedangkan ruang terbuka hijau privat adalah ruang terbuka hijau yang dimiliki oleh perseorangan misalnya seperti kebun halaman rumah/gedung milik masyarakat atau swasta yang terdapat tanaman. Ruang terbuka hijau publik memiliki presentase minimal $30 \%$ dari luas keseluruhan lahan agar dapat menjamin keseimbangan ekosistem kota baik dalam sistem hidrologi, sistem mikroklimat, maupun sistem lain yang dapat meningkatkan fungsi dan proporsi ruang terbuka hijau kota. Sedangkan presentase ruang terbuka publik minimal sebesar $20 \%$ yang disediakan oleh pemerintah kota agar lebih dijamin pencapaiannya sehingga memungkinkan pemanfaatannya secara luas oleh masyarakat. Pemanfaatan ruang terbuka hijau lebih kearah tamanam atau tumbuh-tumbuhan secara alamiah ataupun budidaya tanaman seperti lahan pertanian, pertamanan, perkebunan dan sebagainya (Pemendagri No.1, 2007 Tentang Penataan Ruang Terbuka Hijau Di Kawasan Perkotaan).

Selain sebagai sarana perkembangan interaksi sosial dalam sebuah kawasan, ruang terbuka hijau juga memiliki peran yang cukup penting dalam menjaga sistem ekologis lingkungan serta mendukung unsur estetika lingkungan (Hidayah, 2012). Secara umum fungsi ruang terbuka hijau menurut Permendagri No.1 Tahun 2007 Tentang Penataan Ruang Terbuka Hijau Kawasan Perkotaan menyatakan bahwa fungsi ruang terbuka hijau adalah:

a. Areal perlindungan berlangsungnya fungsi ekosistem dan penyangga kehidupan.

b. Sarana menciptakan kebersihan, kesehatan, keserasian dan keindahan lingkungan.

c. Sarana rekreasi masyarakat.

d. Sarana pengaman lingkungan hidup perkotaan terhadap berbagai macam pencemaran baik di darat, perairan, dan udara. e. Sarana penelitian dan pendidikan serta penyuluhan bagi masyrakat untuk membentuk kesadaran lingkungan.

f. Tempat perlindungan plasma nutfah.

g. Sarana untuk mempengaruhi dan memperbaiki iklim mikro.

h. Sebagai pengaturan tata air.

Keberadaan ruang terbuka hijau dimaksudkan sebagai penghijauan pada kota yang mencakup unsur kenyamaan dan keindahan. Unsur kenyamanan berupa peredam kebisingan, peneduh dan pembersih udara. Unsur keindahan berupa penataan tanaman dengan konstruksi-konstruksi tertentu. Pada penerapannya, ruang terbuka hijau menggunakan prinsip komposisi desain yang baik (Hamid Shirvani, 1985).

\section{METODE}

Penelitian ini merupakan jenis penelitian kualitatif dengan metode deskriptif yang melakukan analisis kondisi empirik sebagai sumber informasi atau data. Penelitian kualitatif dapat dilakukan dengan cara melakukan survei melalui observasi lapangan, wawancara dan studi literatur. Jenis data yang digunakan dalam penelitian ini adalah data primer dan data sekunder. Data primer didapat melalui observasi lapangan yaitu pengamatan langsung terhadap kondisi faktual di lapangan dengan merasakan ruang, pengumpulan data berbentuk hasil wawancara dan dokumentasi berupa foto. Sedangkan data sekunder didapat melalui studi literatur yaitu metode yang digunakan untuk mengumpulkan data-data atau toeri-teori yang berhubungan dengan topik yang diangkat dalam penelitian melalui buku, jurnal, artikel laporan penelitian dan informasi dari internet sehingga akan terkumpul referensi yang relevan dengan permasalahan.

Jenis metode yang digunakan dalam proses analisis data adalah dengan metode analisisdeskriptif yang dilakukan dengan cara menguraikan dan menganalisis secara menyeluruh data dan fakta empirik yang telah dikumpulkan sebelumnya kemudian menguraikannya menjadi sebuah paragraf deskripsi agar mudah dimengerti dan dipahami.

\section{HASIL DAN PEMBAHASAN}


Bangunan Gedung Pendidikan Dokter Fakultas Kedokteran merupakan salah satu gedung di Universitas Sebelas Maret yang sudah menerapkan sistem penghawaan alami. Sistem penghawaan alami pada bangunan diterapkan pada hall yang berada di lantai satu bangunan. Hall dimanfaatkan sebagai ruang penerimaan dan sirkulasi pengguna gedung yang akan mengakses sarana dan prasarana yang tersedia pada gedung melalui tangga maupun lift yang tersedia seperti pada Gambar 4.

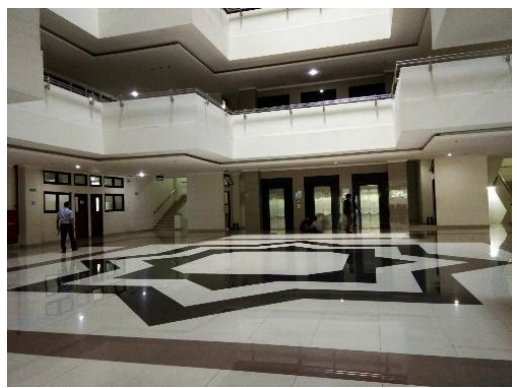

Gambar 4. Hall Lantai Satu Gedung Pendidikan Dokter Fakultas Kedokteran

Pada lantai satu terdapat beberapa inlet yaitu pada main entrance bangunan yang berada pada sisi sebelah barat dan side entrance yang berada pada sisi sebelah utara dan selatan. Pada main entrance pintu dibiarkan terbuka setiap saat agar memudahkan pengguna gedung dalam mengakses bangunan dan pada side entrance pintu hanya dibuka pada saat-saat tertentu sehingga pada hari-hari biasa dibiarkan dalam keadaan tertutup, lihat Gambar 6. Hal ini menyebabkan pada hari-hari biasa udara yang masuk menuju lantai satu hanya melalui main entrance saja. Kapasitas udara yang masuk juga tidak maksimal karena posisi main entrance yang menjorok ke dalam sehingga sirkulasi udara terhalang oleh dinding-dinding yang berada pada samping main entrance. Kurangnya inlet pada hall menyebabkan tidak adanya dorongan angin yang cukup kuat untuk membuat sirkulasi udara naik keatas menuju outlet, seperti pada Gambar 5.

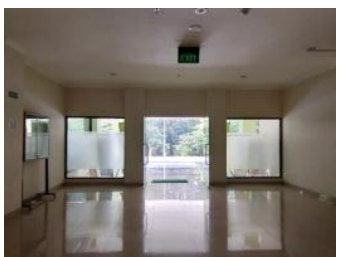

Pintu Main Entrance

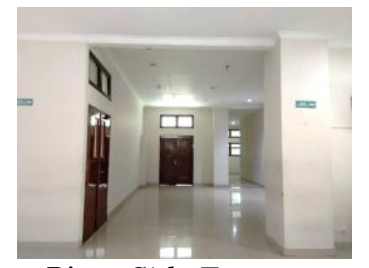

Pintu Side Entrance
Gambar 5. Akses bangunan/entrance

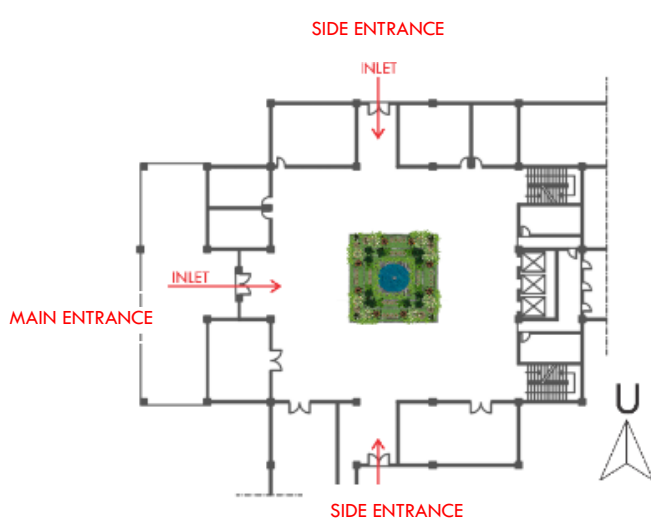

Gambar 6. Denah Lantai Satu Gedung Pendidikan Dokter UNS

Sistem penghawaan alami pada bangunan yang diterapkan pada hall lantai satu bangunan dimulai dari masuknya angin pada main entrance bangunan di sisi sebelah barat masuk menuju hall lantai satu, lihat Gambar 6. Angin yang memiliki tekanan udara tinggi ini kemudian bergerak menuju daerah dengan tekanan udara rendah yaitu pada hall lantai satu dan diteruskan melalui void yang terletak di tengah bangunan menuju lantai-lantai yang berada di atasnya. Angin dari selasar setiap lantai kemudian dibuang keluar menuju outlet yang berada di setiap lantai berupa lubanglubang kecil yang diletakkan pada sisi luar bangunan. Pergerakan angin menuju lantai atas ini disebabkan pada atas void bangunan ditempatkan skylight dengan ukuran 36 m x 36 $\mathrm{m}$ yang berfungsi untuk mendukung pencahayaan alami pada bangunan. Udara yang berada di bawah skylight memiliki suhu yang tinggi dengan tekanan yang rendah sehingga udara dari bawah yang memiliki suhu rendah dengan tekanan tinggi naik ke atas mengisi udara dengan tekanan rendah tadi, lihat Gambar 7. Pengaplikasian skylight pada bangunan juga menyebabkan terganggunya kenyamanan termal pada bangunan terutama pada lantai yang dekat dengan skylight. Sehingga mengganggu kenyamanan pengguna dalam beraktivitas sehari-hari. Namun demikian, potensi terang alami sebaiknya perlu untuk diaplikasikan sebagaimana prinsip dari arstektur hijau yakni desain bangunan yang mempertimbangkan kolaborasi dengan daya dukung iklim (Brenda, 1991). 


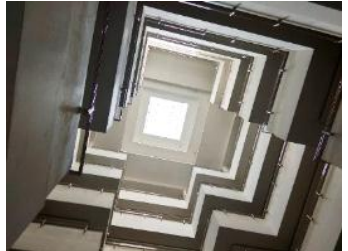

Lantai dasar

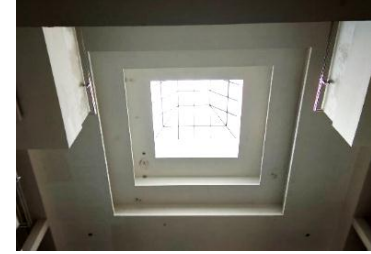

Atap Bangunan

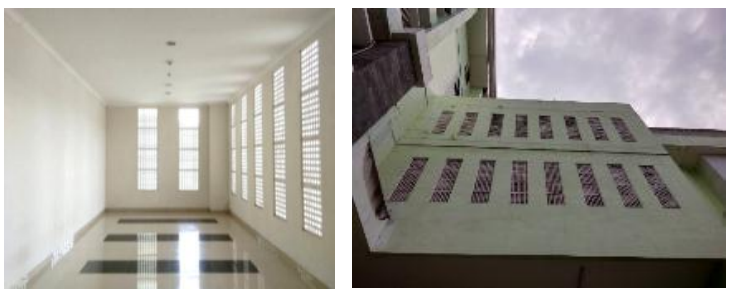

Gambar 8. Outlet Pada Lantai Atas Bangunan

Sistem outlet dan inlet untuk mendukung penghawaan alami yang berada pada hall lantai satu pada Gambar 8, masih belum maksimal. Hal ini disebabkan karena kurangnya jumlah inlet dan outlet pada lantai satu sehingga sistem sirkulasi udara belum dapat dikatakan maksimal. Respon dalam menangani kondisi eksisting permasalahan inlet dan outlet yang belum optimal dapat dilakukan dengan penambahan jumlah inlet tanpa mengubah konstruksi gedung yaitu dengan membiarkan pintu pada side entrance pada sisi utara dan selatan terbuka sepanjang hari. Hal ini dikarenakan sesuai dengan arah angin yang dominan berhembus dari arah selatan ke utara pada musim kemarau dan dari utara ke selatan pada musim penghujan. Sehingga kapasitas udara yang masuk menuju bangunan khususnya lantai satu dapat bertambah daripada biasanya. Skylight yang terletak pada bagian atas void berfungsi sebagai pendukung pencahayaan alami pada bangunan. Secara tidak sadar pengaplikasian skylight pada atap bangunan juga turut berperan dalam mendukung sistem penghawaan alami karena udara yang berada di bawah skylight menjadi panas dan menyebabkan udara yang masuk ke hall naik melalui void menuju ke lantai atas pada selasar, lihat Gambar 8. Namun udara yang masuk melalui pintu hall memiliki sifat yang kering sehingga mengganggu aktivitas pengguna gedung. Oleh karena itu perlu adanya penanganan khusus yaitu berupa penyediaan ruang hijau pada bangunan. Ruang hijau nantinya akan diletakkan pada bagian bawah skylight yang terletak segaris lurus dengan void bangunan. Ruang hijau ini membuat udara yang masuk melalui hall menjadi sejuk dikarenakan terjadi pertukaran udara pada tanaman-tanaman yang disusun pada ruang hijau. Pertukaran udara ini menyebabkan udara kering yang masuk berubah menjadi udara sejuk dengan suhu yang rendah dan tekanan udara yang tinggi sehingga memungkinkan adanya sirkulasi udara yang bergerak dari bawah menuju ke atas dan terdistribusi ke selasar setiap lantai. Sirkulasi terjadi karena sesuai dengan Hukum Buys Ballot yang menyebutkan bahwa udara akan bergerak dari tekanan udara tinggi yaitu udara dingin dengan suhu rendah menuju tekanan rendah yaitu udara panas dengan suhu tinggi. Udara yang berada di ruang hijau merupakan udara dingin dengan tekanan tinggi dan udara yang berada di bawah skylight merupakan udara panas dengan tekanan rendah sehingga udara dingin akan bergerak ke atas dan mengisi udara panas. Selain sebagai pendukung sistem penghawaan alami, ruang hijau pada bangunan juga memperindah hall. Hal ini dikarenakan desain interior Gedung Pendidikan Dokter terkesan monoton. Oleh karenanya, menghadirkan desain hijau dengan memberi taman indoor untuk menambah kualitas ruang dalam bangunan.

Jenis tanaman yang digunakan pada hall lantai satu Gedung Pendidikan Dokter merupakan jenis tanaman indoor dikarenakan tanaman berada di dalam hall yang secara tidak langsung terkena paparan sinar matahari. Tanaman yang digunakan pada ruang hijau memiliki beberapa dari kriteria yang tercantum dalam Tabel 1 berikut :

Tabel 1. Kriteria Tanaman

\begin{tabular}{|c|l|}
\hline No. & \multicolumn{1}{|c|}{ Kriteria Tanaman } \\
\hline 1. & Memiliki daun yang tebal, liat, dan kaku \\
\hline 2. & $\begin{array}{l}\text { Permukaan daun mengkilap karena banyak } \\
\text { diselimuti zat lilin }\end{array}$ \\
\hline 3. & $\begin{array}{l}\text { Membutuhkan intensitas sinar matahari yang } \\
\text { rendah }\end{array}$ \\
\hline 4. & $\begin{array}{l}\text { Tahan terhadap udara kering dengan sedikit } \\
\text { sirkulasi udara }\end{array}$ \\
\hline 5. & $\begin{array}{l}\text { Tahan terhadap temperatur sedang serta } \\
\text { perbedaan temperatur siang dan malam yang } \\
\text { ekstrem }\end{array}$ \\
\hline
\end{tabular}

Berdasarkan kriteria yang telah ditentukan maka tanaman yang dapat digunakan untuk mengisi ruang hijau pada hall lantai satu yaitu: Maranta Batik merupakan tanaman yang memiliki daun lebar berwarna hijau tua. Daun 
maranta yang lebar dihiasi dengan garis-garis berwarna putih sehingga dapat menambah keindahan tanaman. Garis-garis putih inilah yang membuat tanaman ini terlihat menggunakan motif batik. Maranta Batik merupakan jenis tanaman yang sedikit membutuhkan air dan akan mati apabila tanaman terlalu banyak disiram apalagi hingga air menggenang dalam pot. Tanaman juga dapat hidup pada tempat yang sedikit terpapar sinar matahari sehingga sangat cocok ditempatkan di dalam ruangan. Maranta Batik dapat dilihat pada Gambar 9. Tanaman sansevieria atau sering disebut bunga lidah mertua merupakan tanaman yang dapat bertahan hampir di lingkungan apapun. Tumbuhan ini memiliki daun keras yang bisa mentolerir cahaya rendah meskipun kebanyakan berkembang dalam cahaya medium atau terang. Sansevieria tumbuh sangat baik pada temperatur 15 hingga 30 derajat celcius. Sansevieria dapat dilihat pada Gambar 9.

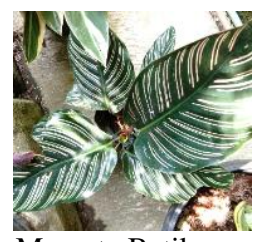

Maranta Batik

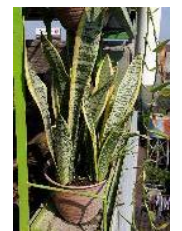

Sansevieria

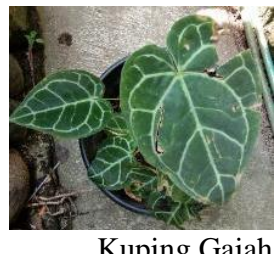

Kuping Gajah
Gambar 9. Sansevieria dan Kuping Gajah

Anthurium Crystallinum atau yang sering disebut Kuping Gajah merupakan tanaman hias dengan daun yang lebar dan tebal. Daun sedikit mengkilap dengan selimut berupa lapisan lilin. Daun tanaman juga menyerupai kuping gajah dengan warna daun hijau tua dan urat-urat daun berwarna putih. Kuping Gajah cocok untuk tanaman indoor karena tidak membutuhkan sinar matahari dengan intensitas tinggi. Visual tanaman Anthurium Crystallinum dapat dilihat pada Gambar 9. Anthurium Andraeanum merupakan tanaman keluarga Araceae. Tanaman ini biasanya hidup secara epifit dengan menempel di batang pohon atau dapat juga hidup secara terrestrial di dasar hutan. Daya tarik tanaman ini adalah bentuk daunnya yang indah, unik, dan bervariasi dengan warna hijau tua dan tulang daun besar menonjol. Anthurium Andraeanum memiliki daun yang berlapis lilin dan tidak membutuhkan sinar matahari yang banyak sehingga cocok di tempatkan dalam ruang. Anthurium Andraeanum dapat dilihat pada
Gambar 10. Dracaena Reflexa merupakan tanaman dengan daun yang memanjang berwarna kuning hingga krem pada pinggir daunnya. Tanaman ini juga dapat menyerap racun dari udara dan dapat tumbuh dengan baik pada suhu ruangan bahkan dalam udara kering seperti ruangan AC. Selain itu tanaman ini juga dapat tumbuh pada kondisi kekurangan cahaya sekalipun. Dracaena Reflexa dapat dilihat pada Gambar 10.

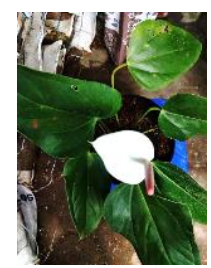

Anthurium Andraeanum

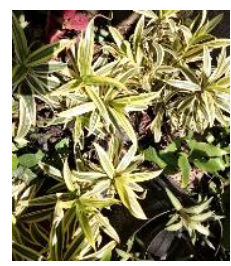

Dracaena Reflexa

Gambar 10. Anthurium Andraeanum dan Dracaena Reflexa

Rekomendasi desain yang disarankan, yakni menyediakan ruang hijau pada area hall agar udara dalam araea tersebut menjadi lebih sejuk. Tata letak dan pola ruang hijau disajikan pada Gambar 11.

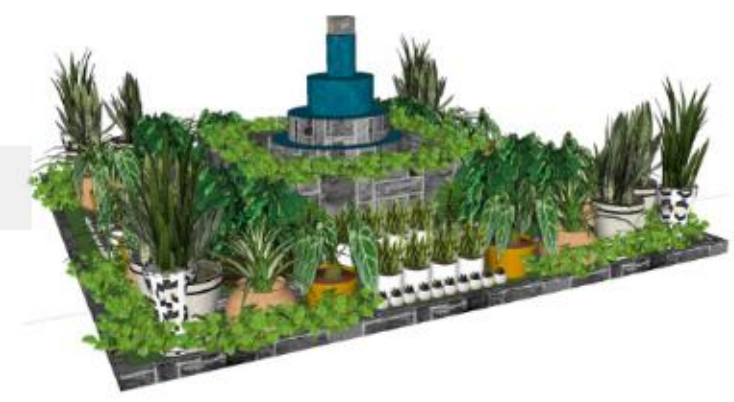

Gambar 11. Perspektif Desain Ruang Hijau Pada Hall

Dalam tampak dua dimensi, desain ruang hijau pada hall divisualisasikan pada Gambar 16. Pola tata hijau dengan mempertimbangkan tinggi dan corak daun maupun tanaman. Tanaman indoor yang berukuran lebih tinggi diletakkan pada tepian taman agar dapat menjadi pembatas area hijau. Pada bagian tengah depan diisi dengan tanaman yang lebih rendah dengan corak daun bervariasi yang diatur secara rapi agar memberikan nilai estetika taman. Pada bagian tengah ruang hijau, dibuat kolam indoor yang berfungsi untuk memberi efek passive cooling atau pendinginan pasif yang dapat menambah kesejukan ruang. Tanaman lain yang berdaun memanjang 
diletakkan pada area grid untuk mempertegas visual taman, lihat tampak samping pada Gambar 12 dan tampak atas pada Gambar 13.

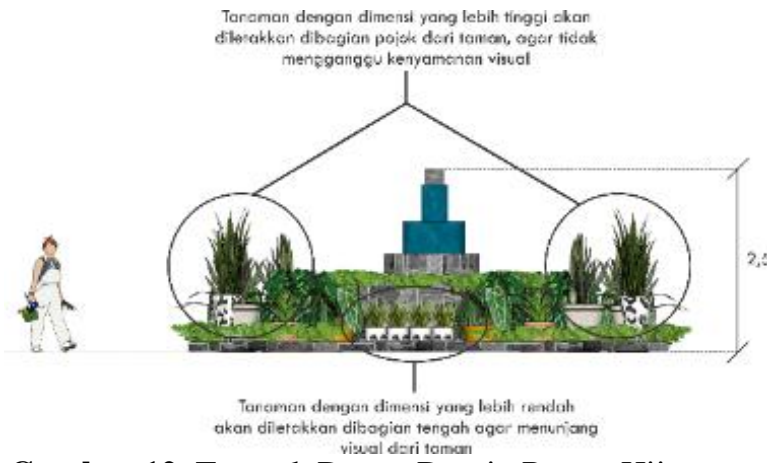

Gambar 12. Tampak Depan Desain Ruang Hijau Pada Hall

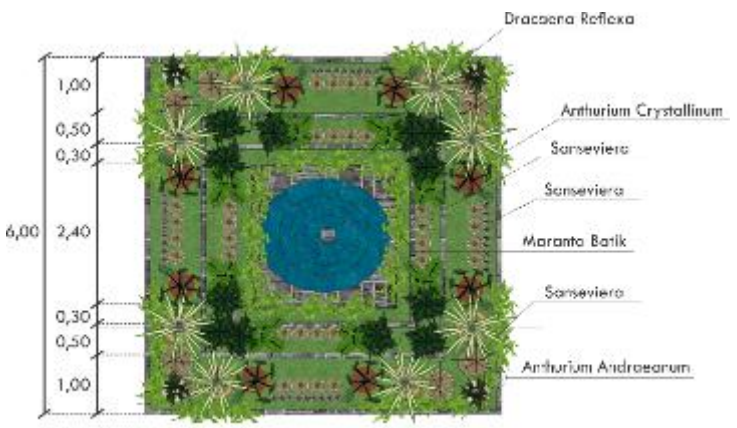

Gambar 13. Tampak Atas Desain Ruang Hijau Pada Hall

Sistem penghawaan alami berdasarkan prinsip arsitektur hijau pada bangunan gedung Pendidikan Dokter Fakultas Kedokteran Universitas Sebelas Maret dengan solusi desain melalui optimalisasi bukaan silang yaitu angin yang mempunyai sifat kering masuk melalui inlet yang berada di main entrance dan side entrance hall lantai satu, lihat Gambar 14. Angin ini kemudian menuju ke ruang hijau yang berada di tengah hall dan berada segaris lurus dengan void bangunan.

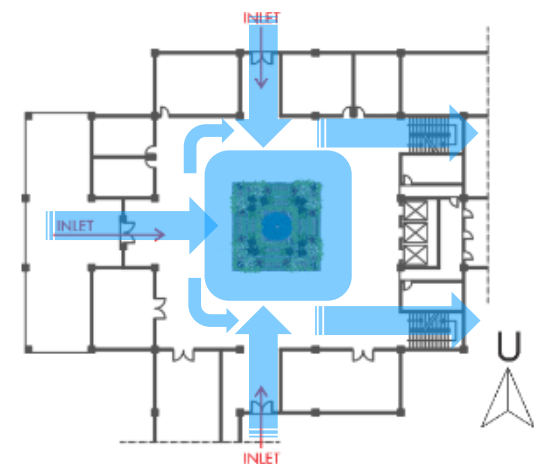

Gambar 14. Sistem Penghawaan Alami Pada Denah
Angin yang memiliki sifat kering berubah menjadi sejuk karena terjadinya proses fotosintesis melalui pertukaran karbondioksida yang dibawa angin dengan oksigen yang dihasilkan oleh tumbuhan. Angin yang berubah menjadi sejuk ini memiliki tekanan udara tinggi dan suhu yang rendah sehingga angin bergerak melalui void menuju ke selasar yang berada di setiap lantai bangunan.

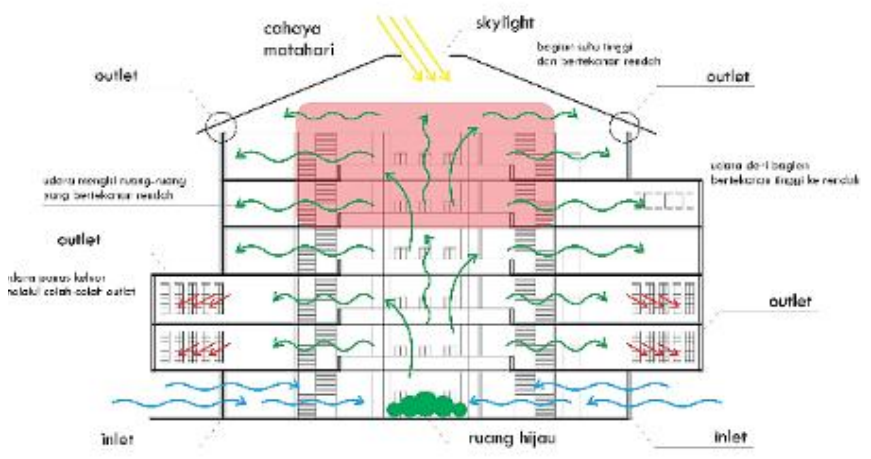

Gambar 15. Sistem Penghawaan Alami Pada Potongan

Pola aliran angin secara horisontal mengalami penerusan arah secara vertikal karena angin yang berada sekitar skylight di bagian atas void bangunan memiliki tekanan udara yang rendah dan memiliki suhu yang tinggi sehingga mengalami pemuaian dan partikel-partikel udara tersebut memiliki kerapatan yang renggang. Angin yang memiliki tekanan tinggi dan suhu rendah yang berasal dari bawah kemudian akan mengisi ruang pada udara panas yang berada di atas. Udara yang naik juga terdistribusi menuju selasar yang berada di setiap lantai. Udara ini kemudian akan keluar melalui outlet yang ada pada permukaan terluar bangunan berupa lubang-lubang berbentuk kotak kecil seperti pada Gambar 15. Pola sirkulasi udara yang lebih merata dan berpotensi melaju ke setiap lantai dengan kehadiran ruang hijau diharapkan mampu mengoptimalkan sirkulasi udara alami dengan pola cross ventilation dan stack ventilation sehingga ruangan dalam gedung menjadi lebih nyaman.

\section{KESIMPULAN}

Penghawaan alami pada bangunan Gedung Pendidikan Dokter Fakultas Kedokteran dapat lebih optimal dengan bukaan dari side entrance 
untuk memperlancar sirkulasi udara yang masuk dan penambahan ruang hijau yang diletakkan di bawah void hall lantai satu. Angin yang masuk melalui pintu utama menuju bangunan memiliki sifat kering dan untuk mendinginkannya melalui implementasi desain hijau yang berada pada tengah hall lantai satu yang selanjutnya disalurkan ke selasar setiap lantai serta dikeluarkan lewat outlet yang berada pada permukaan terluar bangunan.

Ruang hijau pada tengah hall didesain dengan berbagai jenis tanaman khusus yang digunakan untuk area indoor sehingga tidak terlalu membutuhkan sinar matahari. Selain sebagai pendukung penghawaan alami, tanaman juga berfungsi untuk memperindah visual bangunan gedung yang terkesan kaku dan monoton. Ruang hijau nantinya akan membantu menyediakan angin sejuk yang tentunya akan mendukung kenyamanan termal pengguna gedung Pendidikan Dokter Fakultas Kedokteran Universitas Sebelas Maret.

Implementasi desain hijau di area atrium dapat diterapkan pada bangunan lain yang mempunyai kesesuaian pola perletakan dengan bangunan ini. Desain hijau pada area atrium bermanfaat untuk menurunkan suhu ruang, meningkatkan nilai estetika yang dapat menyemangati pengguna, meningkatkan kualitas udara yang mendukung kesehatan dan dapat menghemat energi yang dikonsumsi untuk pengkondisian buatan dan pencahayaan buatan. Strategi implementasi desain hijau pada bangunan tinggi di Fakultas Kedokteran UNS ini memperkuat teori arsitektur hijau Brenda dan Robert Vale (1991) serta prinsip penghawaan alami Stephen dan Andrew (2004) bahwa desain harus memiliki hubungan kerjasama dengan iklim lokal setempat melalui pemanfaatan daya dukung iklim pada bangunan agar tercapai konservasi energi bangunan tinggi.

\section{UCAPAN TERIMAKASIH}

Tim peneliti mengucapkan terimakasih kepada LPPM UNS, yang telah mendukung penelitian ini melalui Skema Penelitian Unggulan Terapan Dana PNBP Universitas Sebelas Maret Tahun Anggaran 2018 dengan nomor kontrak 542/UN27.21/PP/2018. Artikel ini merupakan produk luaran penelitian yang berkolaborasi dengan mahasiswa peserta mata kuliah Arsitektur Hijau.

\section{REFERENSI}

ASHRAE. (1992). Thermal Environmental Conditions for Human Occupancy. Standard 55-1992. American Society of Heating, Refrigerating, and AirConditioning Engineers, Atlanta,USA.

Brenda \& Robert Vale. (1991). Green Architecture, Design for an energyconscious future. London: Bulfinch Press.

Dea Sekar D.A, Gunawan, Sri Yuliani. (2018). Aplikasi Konsep Arsitektur Tropis Pada Bangunan SMP Alam Lebah Putih Salatiga. Arsitektura, Volume 16 Nomor 1 April, DOI: I: http://dx.doi.org/10.20961/arst.v16i1.1 7928, 5-14.

Hidayah, Retna. (2012). Tata Bangunan dan Lingkungan. Diktat Matakuliah TBDL tidak dipublikasikan. Yogyakarta : PPS UNY.

McDowall, Robert. (2008). Fundamental of HVAC System, 32-42.

Republik Indonesia. (2007). Peraturan Menteri Dalam Negeri No.1 Tahun 2007 tentang Penataan Ruang Terbuka Hijau di Kawasan Perkotaan. Sekretariat Negara. Jakarta.

Republik Indonesia. (2007). Undang-Undang No.26 Tahun 2007 tentang Penataan Ruang. Lembaran Negara RI Tahun 2007, No.4 . Sekretariat Negara. Jakarta.

Shirvani, Hamid. (1985). The Urban Design Process. New York : Van Nostrand Reinhold Company.

Stephen R Livermore, Andrew W Woods. (2004). Strategies for Air Movement. Jurnal Elsevier: Building and Environment.

Sulthoni Muhammad. (2011).Penghawaan Alami.http://slendroo.blogspot.co.id/2011/ 10/penghawaan-alami.html. 3 April 2018. Pukul 16.30 WIB. 